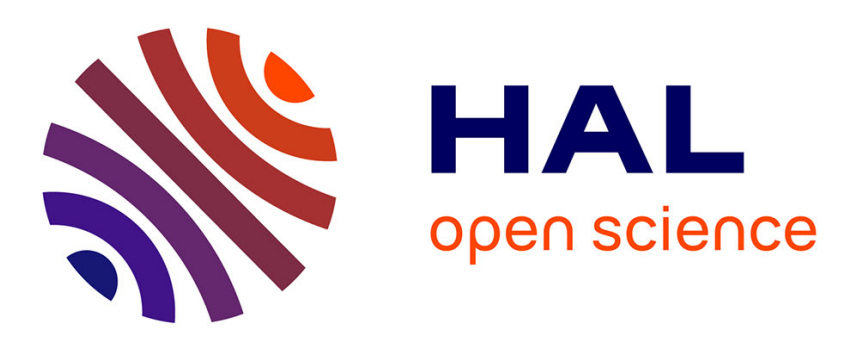

\title{
Role of Carbon, Nickel and Iron Impurities on the Properties of the U-0.2\% V Alloys
}

C. Thiebaut, C. Bonnet, J.-M. Morey

\section{To cite this version:}

C. Thiebaut, C. Bonnet, J.-M. Morey. Role of Carbon, Nickel and Iron Impurities on the Properties of the U-0.2\% V Alloys. Journal de Physique IV Proceedings, 1995, 05 (C7), pp.C7-301-C7-306. 10.1051/jp4:1995736 . jpa-00254030

\section{HAL Id: jpa-00254030 https://hal.science/jpa-00254030}

Submitted on 1 Jan 1995

HAL is a multi-disciplinary open access archive for the deposit and dissemination of scientific research documents, whether they are published or not. The documents may come from teaching and research institutions in France or abroad, or from public or private research centers.
L'archive ouverte pluridisciplinaire HAL, est destinée au dépôt et à la diffusion de documents scientifiques de niveau recherche, publiés ou non, émanant des établissements d'enseignement et de recherche français ou étrangers, des laboratoires publics ou privés. 


\title{
Role of Carbon, Nickel and Iron Impurities on the Properties of the $\mathrm{U}-\mathbf{0 . 2 \%} \mathrm{V}$ Alloys
}

\author{
C. Thiebaut, C. Bonnet and J.-M. Morey
}

Commissariat à l'Energie Atomique, Service Métallurgie Mécanique, Centre de Valduc, 21120 Is-sur-Tille, France

\begin{abstract}
After reviewing briefly the influence of the incorporation of vanadium in the uranium matrix (for contents between 0.0 and 0.5 ), we will examine the effect of major impurities, mainly carbon, nickel and iron, on the properties of the uranium $-0.2 \%$ vanadium alloys. Tensile tests at both ambient and elevated temperatures were conducted, together with some compression tests of cylinders in isothermal conditions, under primary vacuum. The results of these tests will be discussed in connection with metallurgical observations : viz, the growth of the grain boundaries and the recrystallization phenomena will be briefly examined and compared with the mechanical results.
\end{abstract}

\section{INTRODUCTION}

Many uranium alloys have been studied so far : some having a high alloy content, such as U-Mo $10 \%$, U$\mathrm{Nb} 2.5-\mathrm{Zr} 7.5$ (Mulburry) or U-Nb6\% and some others with a rather lower content, such as U-Ti0.75\%, UV $0.2 \%$ or the SICRAL alloys (U-Si-Cr-Al). The effects of the impurities were studied especially for hydrogen and carbon. The goal of this study is to see how the U-V $0.2 \%$ alloy reacts when we purposely include some iron or nickel impurities at levels reaching as much as $300 \mathrm{ppm}$.

After a summary of the role of vanadium in refining the grain size of uranium and improving the mechanical properties, we will describe the influence of the impurities on the U-V $0.2 \%$ alloy. We will then describe the way the ingots were prepared and also give details of the tensile tests, the upsetting and the metallography observations done through this study. In the discussion, we will define the effect of iron and nickel on the alloy, before concluding.

\section{ROLE OF VANADIUM}

The role of the addition of a vanadium content varying between 0.1 and $1 \%$ was studied several years ago by R.Reisse [1] and C.Collot et al. [2]. We will now describe briefly the impact of this addition on the structure and the mechanical properties of uranium.

Pure uranium, at ambient temperature, consists of an $\alpha$ phase polycrystal, orthorhombic which is heterogeneous and has large grain size : typical values are between 0.1 millimetre and a few millimetres. The mean mechanical properties for this metal are then:

Tensile strength : $\mathrm{Rm}=430 \mathrm{MPa}$

Yield strength $\operatorname{Re} 0.2 \%=170 \mathrm{MPa}$

Tensile elongation $\mathrm{A} \%=5 \%$

Furthermore, the crystal behaves as being non isotropic, i.e. :

In the [100] direction, dilatation is $36.710^{-6} /{ }^{\circ} \mathrm{C}$.

In the [010] direction, dilatation is $-9.310^{-6} /{ }^{\circ} \mathrm{C}$.

In the [001] direction, dilatation is $34.210^{-6} /{ }^{\circ} \mathrm{C}$. 
Although it is possible to refine the grain size through deformation, it is preferable to use the effect of small additions of some elements such as vanadium. Additions of 0.1 to $1 \%$ of vanadium were studied by R. Reisse [1], and it was demonstrated that with a carbon content lower than $150 \mathrm{ppm}, 0.2 \%$ of vanadium is sufficient to refine the grain size, whereas when the carbon concentration increases, it is necessary to increase the vanadium content up to $0.3 \%$. It is then no longer possible to use the alloy with a process which includes quenching conditions because cracks then appear with this $0.3 \%$ content. The refinement is done through a controlled cooling rate between the $\beta$ phase (stable between $770^{\circ} \mathrm{C}$ and $665^{\circ} \mathrm{C}$ ) and the $\alpha$ phase (stable below $665^{\circ} \mathrm{C}$ ).

We give here the results for the U-V $0.2 \%$ alloy obtained with a cooling rate near $20^{\circ} \mathrm{C} / \mathrm{mn}$ at the $\beta / \alpha$ transition which is near $665^{\circ} \mathrm{C}$. The grain size then varies between 50 and 100 microns and the mechanical properties are as follows $: \mathrm{Rm}=790 \mathrm{MPa}$ and $\mathrm{A} \%=21 \%$.

We will now see the influence of the main impurities.

\section{ROLE OF CONTAMINANTS}

\subsection{Kinds of contaminants}

Major contaminants to uranium alloys can be briefly listed as follows :

1 - hydrogen [3] : coming from the salt-bath heating, during heat-treatment, from thermomechanical fabrication and from water quenching and more generally during cooling. Its effects are mainly seen as a loss of strength and ductility at temperatures below $100^{\circ} \mathrm{C}$, due to a weakening of grain boundary cohesion, although no preferential precipitation of uranium hydride is generally observed at grain boundaries. Eckelmeyer [4] gives the evolution of the ductility of the U-Ti $0.75 \%$ alloy versus hydrogen content. A very low content of hydrogen ( $2 \mathrm{ppm}$ ) is sufficient to decrease elongation from 25 to $10 \%$.

2 - oxygen : oxygen may come from oxide either from metal, or the vanadium addition, or the residual pressure in the vacuum furnace. It combines very rapidly with uranium and thus forms an oxide which can be found at the end of melting in the upper part of the ingots with controlled solidification.

3 - carbon : we have seen the influence of carbon in the U-V system. With as little as $150 \mathrm{ppm}$, it diminishes the effects of the $0.2 \%$ of vanadium addition. It may come either from the uranium, or from the carbon crucible and the mould which are used with an yttria-stabilized zirconia layer.

4 - iron : this comes from the process of preparation of the uranium metal. The normal content is below $50 \mathrm{ppm}$. But higher levels are sometimes found. The goal of the study is to have an idea of the maximum acceptable values for this impurity.

5 - nickel : same as iron.

\subsection{Preparation}

A standard analysis of the depleted uranium, provided by COGEMA, is given in table 1.

Table $1:$ standard analysis of uranium provided by COGEMA

\begin{tabular}{|c|c|c|c|c|c|c|c|c|c|c|}
\hline \hline Elements & $\mathrm{Fe}$ & $\mathrm{Al}$ & $\mathrm{Ni}$ & $\mathrm{Cu}$ & $\mathrm{Cr}$ & $\mathrm{Si}$ & $\mathrm{C}$ & $\mathrm{O}$ & $\mathrm{N}$ & $\mathrm{H}$ \\
\hline Conc.(ppm) & 50 & 30 & 30 & 30 & 10 & 50 & 100 & 70 & 40 & 1.5 \\
\hline
\end{tabular}

The fusion operation is performed under secondary vacuum, with induction heating and mixing, in carbon crucibles, covered with an yttria-stabilized zirconia plasma sprayed thin layer. The vanadium is soluble at high level $(2.8 \%)$ in the $\gamma$ phase $:$ with quantities less than or equal to $1 \%$, there are no problems of solution during preparation. The liquid metal is heated up to $1400^{\circ} \mathrm{C}$, then held at that temperature for 15 minutes. The casting is made at a temperature of $1350^{\circ} \mathrm{C}$ and we use imposed solidification from the bottom to the top by imposing a temperature gradient : the mould is heated up to $950^{\circ} \mathrm{C}$ at the top and only up to $650^{\circ} \mathrm{C}$ at the bottom. 
Table 2 gives the values of the concentrations of vanadium, carbon, iron and nickel which were analysed in the ingots that were processed for this study. We made 7 melts, varying the contents of the contaminants, iron and nickel in particular.

Table 2 : analysis of the concentration of vanadium, carbon, iron and nickel of the ingots produced for this study.

\begin{tabular}{|c|c|c|c|c|}
\hline \hline Reference $\mathbf{N}^{\circ}$ & $\begin{array}{c}\text { Vanadium } \\
(\mathrm{ppm})\end{array}$ & $\begin{array}{c}\text { Carbon } \\
(\mathrm{ppm})\end{array}$ & $\begin{array}{c}\text { Iron } \\
(\mathrm{ppm})\end{array}$ & $\begin{array}{c}\text { Nickel } \\
(\mathrm{ppm})\end{array}$ \\
\hline 1 & 2215 & 100 & 30 & $<20$ \\
\hline 2 & 2110 & 70 & 168 & $<20$ \\
\hline 3 & 2090 & 90 & 308 & $<20$ \\
\hline 4 & 2120 & 80 & 176 & 164 \\
\hline 5 & 2100 & 90 & 30 & 291 \\
\hline 6 & 2100 & 90 & 30 & 150 \\
\hline 7 & 2115 & 65 & 312 & 309 \\
\hline
\end{tabular}

\subsection{Characterizations}

Two kinds of high temperature characterizations were made :

1 -tensile tests were made at $800^{\circ} \mathrm{C}$ with an initial strain rate of $4.5110^{-2} \mathrm{~s}^{-1}$ with cylindrical specimens, machined directly from the billet.

2 - upsetting tests were conducted with a press of 400 tons, equipped with a furnace, at temperatures ranging between 875 and $900^{\circ} \mathrm{C}$ on workpieces with an initial diameter of $78 \mathrm{~mm}$ and a height of $42 \mathrm{~mm}$. The strain rate is $810^{-4} \mathrm{~s}^{-1}$. Forming was done under primary vacuum with a bisulphur tungsten lubricant. The final form has a thickness of $4 \mathrm{~mm}$.

The results of these tests are given in tables 3 and 4 .

Table 3 : results of the upsetting tests of the U-V $0.2 \%$ alloy

\begin{tabular}{||c|c|c|c|c|c|}
\hline Reference & $\mathrm{T}\left({ }^{\circ} \mathrm{C}\right)$ & Load & \multicolumn{2}{|c|}{ Dimension of the cold disk } & $\mathrm{Rm}$ \\
\hline & & tons & $\begin{array}{c}\text { Diameter } \\
(\mathrm{mm})\end{array}$ & $\begin{array}{c}\text { Thickness } \\
(\mathrm{mm})\end{array}$ & $\mathrm{MPa}$ \\
\hline 1 & 886 & 200 & 255.0 & 3.92 & 4.52 \\
\hline 2 & 892 & 200 & 255.2 & 3.92 & 4.51 \\
\hline 3 & 875 & 200 & 246.0 & 4.19 & 6.02 \\
\hline 4 & 884 & 200 & 251.7 & 4.02 & 5.03 \\
\hline 5 & 884 & 200 & 252.0 & 4.02 & 4.97 \\
\hline 6 & 874 & 200 & 252.5 & 3.99 & 4.88 \\
\hline 7 & 878 & 200 & 254.0 & 3.97 & 4.77 \\
\hline
\end{tabular}

Table $4:$ results of the tensile tests of the U.V $0.2 \%$ alloy at $800^{\circ} \mathrm{C}$.

\begin{tabular}{||c|c|c|c|}
\hline Reference & $\mathrm{T}\left({ }^{\circ} \mathrm{C}\right)$ & $\mathrm{Rm}(\mathrm{MPa})$ & $\mathrm{A} \%(\%)$ \\
\hline 1 & 800 & 5.36 & 128 \\
\hline 2 & 800 & 5.65 & 115 \\
\hline 3 & 800 & 5.76 & 91 \\
\hline 4 & 800 & 5.75 & 100 \\
\hline 5 & 800 & 5.73 & 102 \\
\hline 6 & 800 & 5.29 & 120 \\
\hline 7 & 800 & 5.41 & 129 \\
\hline
\end{tabular}

Tensile tests were also made at ambient temperature $\left(20^{\circ} \mathrm{C}\right)$, on specimens coming out of the foundry after the heat treatment at controlled cooling rate (FT) and from forming with the same heat treatment (MT), using cylindrical specimens 4 millimetres in diameter and 30 millimetres long at an initial strain rate of $5.510^{-4} \mathrm{~s}^{-1}$. Results are given in table 5 . 
Table 5 : results of the tensile tests performed at ambient temperature of the U-V $0.2 \%$ alloy.

\begin{tabular}{||c|c|c|c|c|c|c|}
\hline \hline Référence & $\begin{array}{c}\text { Iron } \\
(\mathrm{ppm})\end{array}$ & $\begin{array}{c}\text { Nickel } \\
(\mathrm{ppm})\end{array}$ & State & $\begin{array}{c}\mathrm{Rm} \\
(\mathrm{MPa})\end{array}$ & $\begin{array}{c}\text { Re0.2 } \\
(\mathrm{MPa})\end{array}$ & $\begin{array}{c}\text { A \% } \\
(\%)\end{array}$ \\
\hline 1 & 30 & $<10$ & F.T. & 915 & 415 & 20.4 \\
\hline & & & M.T. & 940 & 450 & 24.1 \\
\hline 2 & 168 & $<10$ & F.T. & 900 & 405 & 21.7 \\
\hline 3 & & & M.T. & 960 & 470 & 22.1 \\
\hline & 308 & 18 & F.T. & 915 & 430 & 14.3 \\
\hline 4 & 30 & 150 & F.T. & 825 & 410 & 11.8 \\
\hline & & & M.T. & 915 & 450 & 18 \\
\hline 5 & 30 & 291 & F.T. & 840 & 420 & 12.1 \\
\hline & & & M.T. & 870 & 465 & 11.7 \\
\hline 6 & 176 & 164 & F.T. & 830 & 405 & 12.7 \\
\hline & & & M.T. & 855 & 460 & 10.3 \\
\hline 7 & 312 & 309 & F.T. & 710 & 400 & 4.7 \\
\hline & & & M.T. & 805 & 465 & 5.7 \\
\hline
\end{tabular}

Metallographic observations were made with the following results :

* just out of the foundry or after upsetting in the 7 phase, the alloy has a large grain size, whatever the content of iron and nickel. But the more impurities, the larger the grain size.

* after a controlled cooling rate between the $\beta$ and $\alpha$ phases, we have : 1) for iron content less than or equal to $150 \mathrm{ppm}$, refinement of the grain size. 2) for nickel additions, the grain size becomes large and heterogeneous when the content goes from 150 to $300 \mathrm{ppm}$. The refined grain size can be seen in Figure 1; whereas in Figure 2, the effect of the contaminants is clearly seen and the grain size is larger.

\subsection{Discussion}

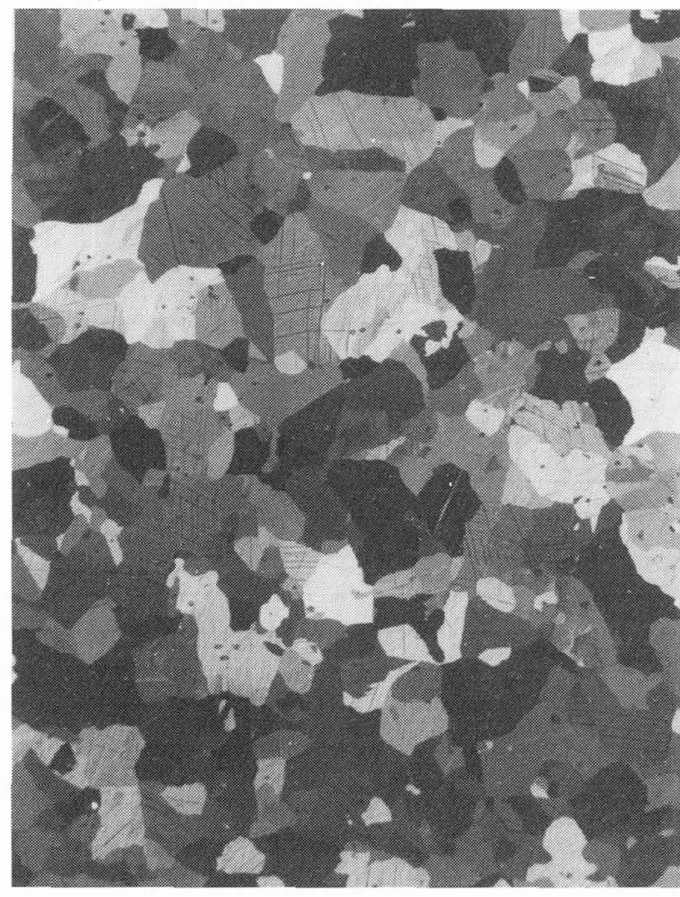

Figure 1 : micrograph of a refined $U-\mathrm{V} 0.2 \%$ alloy

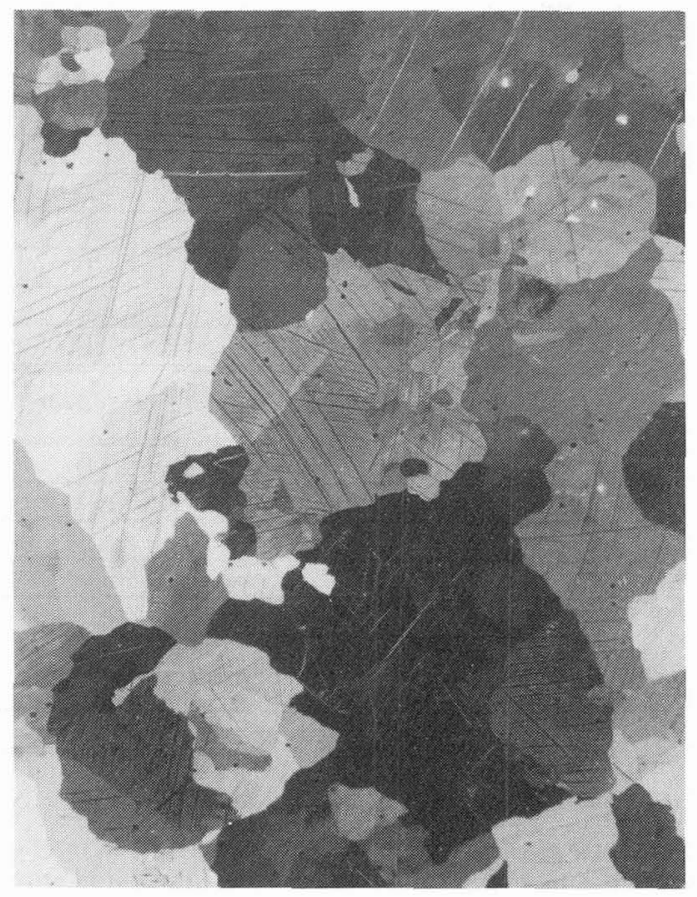

Figure 2 : micrograph of a "contaminated" U-V $0.2 \%$ alloy 
If we look first at the results given for high temperature tests, several things are worth noticing :

* the nickel and the iron content does not seem to influence the tensile strength. But there is a strange value for the workpiece reference $\mathrm{N}^{\circ} 3$ which has a value twenty per cent higher than the others for the upsetting test and which is not confirmed by the tensile test for the Rm value ; on the other hand, elongation is lower for $\mathrm{N}^{\circ} 3(91 \%)$ than for the others (more than 100\%). This may be attributable to some local damage or concentration of impurities (iron).

* The tensile strength values given by the tensile tests are higher than those given by the upsetting test (except for $\mathrm{N}^{\circ} 3$ ) : this can be attributed to the strain rate which is quite 50 times higher for the tensile test (and the yield strength quite often increases when the strain rate does), and/or to the temperature which is lower for the tensile test than for the upsetting test.

* Generally, it can be concluded that at high temperatures, nickel and iron have no role in connection with the mechanical properties : it is not very useful to know their concentrations if we are only concerned with metal forming at high temperatures (i.e. in the $y$ phase which is stable at temperatures above $770^{\circ} \mathrm{C}$ ).

The results at $20^{\circ} \mathrm{C}$ are clear, as are the metallographic observations, which correlate well :

1) When the iron content goes from 0 to $150 \mathrm{ppm}$, elongation remains constant; when it increases further to $300 \mathrm{ppm}$, elongation decreases from 22 to $13 \%$. This correlates well with the grain size, which increases from 80 microns to a few hundreds of microns at the same time, whereas it is close to 80 microns when the iron content varies between 0 and $150 \mathrm{ppm}$.

2) For the ingots containing only nickel, elongation decreases as soon as the concentration reaches $150 \mathrm{ppm}$. Grain size becomes heterogeneous and coarse.

3) For alloys containing both iron and nickel, the effect on the mechanical properties appears as soon as the total content is as high as $300 \mathrm{ppm}$.

4) Whatever the iron and nickel content, the yield strength remains about the same. But the tensile strength decreases when the content of impurities increases, as is demonstrated in Table 5.

All this can be compared with what happens when the carbon content increases : some precipitation takes place such as $\mathrm{V}_{2} \mathrm{C}$ or more complex precipitates like (UVC) composites, and after that precipitation far too little free vanadium remains to refine the grain size. Some reaction of this kind must happen with iron and nickel : there must be some precipitation with either iron or nickel, or both, containing also vanadium, so that the concentration of free vanadium decreases below the threshhold value necessary to refine the grain size. These precipitates were not detected in our observations. We should perhaps have made an ingot with far more iron and nickel in it in order to visualize these precipitates.

\section{CONCLUSION}

The main conclusions for this study can be summarized as follows :

$1 \mathrm{Nickel}$ and iron, for concentrations up to $600 \mathrm{ppm}$, have no influence on the flow characteristics of $U-V 0.2 \%$ alloy in the $\gamma$ phase, either in traction or in compression forming. Only one reservation must be made for the ingot with $300 \mathrm{ppm}$ iron content, which has slightly lower elongation than the others.

2 At $20^{\circ} \mathrm{C}$, after a controlled cooling rate between the $\beta$ and 0 phases, we can distinguish differences among the different melts : from $150 \mathrm{ppm}$ of nickel, or $300 \mathrm{ppm}$ of iron, or $300 \mathrm{ppm}$ of nickel and iron contents, we can observe : a decrease of the tensile strength, a decrease of the tensile elongation, in conjonction with an increase of the grain size from 70 to 300 microns. This is attributed to the formation of a precipitate of a component comprising either iron or nickel (or both components) and vanadium at least (perhaps also uranium).

3 We have to impose a maximum concentration of less than $300 \mathrm{ppm}$ for the total iron and nickel content and a more restrictive concentration of less than $150 \mathrm{ppm}$ for nickel alone in order to be sure that the $0.2 \%$ of vanadium will be sufficient to refine the alloy. 


\section{Acknowledgements}

We are very grateful to the Commissariat à L'Energie Atomique which has authorized us to publish this work, and to all the people who contributed to produce the preparations and characterizations necessary for this study.

\section{References}

[1] Reisse R., Contribution à l'étude des alliages d'uranium faiblement chargés en vanadium, Thésis, LYON, 1972

[2] Collot C., Couterne A. \& Guillaume C., Giraud-Heraud F. \& Guillaumin J., J.Nucl. Materials, 43 (1972), 28-50

[3] Hugues A.N., Orman S. \& Pietor G., some effects of hydrogen in uranium, Bull Sign., 740 (1973), 34/2 N²284, Conf. Int. Paris 1972, Paris Sci. et Ind. "Hydrogène dans les métaux",

[4] Eckelmeyer K.H. \& Zanner F.J., Journal of nuclear Materials, 67 (1977), 33-41 